\title{
Uji Coba Penggunaan Limbah Air Kelapa Tua sebagai Bahan Dasar Media Isolasi
}

\author{
Hanna Yolanda, ${ }^{1}$ Yanti Mulyana ${ }^{2}$ \\ ${ }^{1}$ Departemen Parasitologi Unika Atma Jaya, ${ }^{2}$ Departemen Mikrobiologi Fakultas Kedokteran \\ Universitas Padjadjaran-Rumah Sakit Dr. Hasan Sadikin, Bandung
}

\begin{abstract}
Abstrak
Media pembenihan isolasi yang umumnya digunakan adalah media sintetik yang diimpor dan harganya mahal. Banyak bahan organik yang secara alamiah mengalami pemecahan senyawa organik kompleks menjadi senyawa sederhana oleh mikrob. Berdasarkan pemikiran inilah, peneliti mencoba membuat media isolasi dengan bahan dasar limbah air kelapa tua, sehingga dapat menjadi pertimbangan sebagai media yang lebih ekonomis. Metode penelitian adalah eksperimental laboratorik dengan mengisolasi bakteri uji menggunakan media berbahan dasar air kelapa tua. Media air kelapa tua dikomposisikan menyerupai komposisi agar MacConkey dan lempeng agar darah (LAD). Media standar yang digunakan adalah agar MacConkey dan LAD. Media kontrol yang digunakan adalah media agar $15 \mathrm{~g} / \mathrm{L}$ dan media agar air kelapa tua. Bakteri yang diuji adalah beberapa spesies Enterobacteriaceae dan kokus gram positif. Variabel yang dinilai adalah gambaran makroskopis dan mikroskopis. Analisis data menggunakan teknik Wilcoxon matched pairs test dan sign test. Hasil penelitian menunjukkan perbedaan tidak bermakna $(p>0,05)$ antara media standar dan media air kelapa tua. Gambaran spesifik dari bakteri uji seperti koloni berwarna merah, gambaran mukoid, dan zona hemolitik tampak serupa antara media standar dan media air kelapa tua. Simpulan penelitian ini adalah air kelapa tua dapat dimanfaatkan sebagai bahan dasar media isolasi Enterobacteriaceae dan kokus gram positif. [MKB. 2011;43(3):117-21].
\end{abstract}

Kata kunci: Agar MacConkey, air kelapa tua, isolasi, lempeng agar darah, media

\section{Using Ripe Coconut Waste-Water as Base for Isolation Media Substance}

\begin{abstract}
The culture media commonly used for isolation are imported and expensive. Many organic materials are naturally decomposed from complex organic compounds to simple ones by microbes. Based on this principles, this study wants to make isolation media with ripe coconut waste-water as based substance, so it can be considered as economical culture media. The method was laboratoric experimental by isolating tested bacteria with ripe coconut waste-water as based substance. The composition of the media were adjusted with MacConkey agar and blood agar base. Standard media were MacConkey agar and blood agar base. Control media were agar $15 \mathrm{~g} / \mathrm{L}$ media and ripe coconut waste-water agar media. Tested bacteria were a number species of Enterobacteriaceae and positive gram cocci. The evaluated variables were macroscopic and microscopic images. Data was analized by Wilcoxon matched pairs test and sign test methods. This study did not find a significant differences $(p>0.05)$ between standard media and ripe coconut waste-water media. Specific characteristics of tested bacteria, such as red colonies, mucoid, and hemolitic zone, were similar between standard media and ripe coconut waste-water media. The conclusion is ripe coconut waste-water can be used as base for isolation media substance of Enterobacteriaceae and gram positive cocci. [MKB. 2011;43(3):117-21].
\end{abstract}

Key words: Blood agar base, MacConkey agar, isolation, media, ripe coconut waste-water

Korespondensi: Hanna Yolanda, dr., M.Kes, Departemen Parasitologi Unika Atma Jaya, Jalan Pluit Raya 2 Jakarta Utara 14440, telepon, (021) 6693168 ext 210, mobile 081322285483, e-mail hanna_pole@yahoo.com 


\section{Pendahuluan}

Media perbenihan sangat penting untuk isolasi bakteri. ${ }^{1,2}$ Media perbenihan hingga saat ini masih diimpor dengan harga yang semakin mahal akibat krisis ekonomi. Oleh karena itu, upaya untuk mencari media alternatif lain perlu dilakukan guna mengurangi ketergantungan terhadap media impor.

Indonesia merupakan negara yang kaya akan tanaman kelapa. ${ }^{3}$ Produksi air kelapa cukup berlimpah di Indonesia, namun pemanfaatannya masih kurang terutama air kelapa tua. Air kelapa tua yang terbuang percuma dapat menimbulkan polusi asam asetat yang terbentuk oleh karena fermentasi air kelapa. 3,4

Pada tahun 1976, Sevilla ${ }^{5}$ dari Laboratorium Bureau Manila melakukan uji coba pembuatan media perbenihan air kelapa untuk isolasi Mycobacterium tuberculosis dan Corynebacterium diphtheriae. Pada percobaan ini peneliti membuat media baru dengan mencampurkan air kelapa $300 \mathrm{~mL}, 10$ buah telur, dan 2\% malachite green. Media baru ini dinamakan coconut water egg malachite green medium (CEM). Hasil penelitian ini didapatkan bahwa $M$. tuberculosis dan $C$. diphtheriae tumbuh dengan baik dalam CEM.

Pada tahun 1980, Rockhill dkk. ${ }^{6}$ memodifikasi CEM dengan menambah kalium telurit $187 \mu \mathrm{g} /$ $\mathrm{mL}$ untuk membiakkan $C$. diphtheriae dari apus tenggorok penderita difteria. Media baru ini dinamakan coconut water-tellurite-egg medium (CTEM). Hasil dari penelitian ini adalah sensitivitas CTEM yang sama dengan sensitivitas agar darah telurit sistein dalam menanam $C$. diphtheriae.

Berdasarkan hal-hal di atas, maka pada penelitian ini dilakukan modifikasi limbah air kelapa menjadi media yang dapat berguna bagi perkembangan mikrobiologi kedokteran, khususnya di Indonesia. Bahan dasar yang dipilih adalah air kelapa tua, oleh karena mengandung sejumlah zat gizi dan pemanfaatannya yang masih kurang. Kandungan karbohidrat air kelapa tua lebih sedikit dibandingkan dengan kandungan karbohidrat air kelapa muda. Kandungan karbohidrat air kelapa tua adalah $0,2 \mathrm{~g}$ per $100 \mathrm{~g}$. Kandungan karbohidrat yang sangat sedikit ini diharapkan tidak mempengaruhi proses peragian bakteri terhadap substrat karbohidrat tertentu yang sengaja ditambahkan. Selain itu, kandungan karbohidrat yang sangat sedikit ini diharapkan tidak menghambat produksi hemolisin. ${ }^{4-8}$

\section{Metode}

Penelitian ini merupakan penelitian eksperimental laboratorik dengan mengisolasi beberapa spesies dari Enterobacteriaceae dan kokus gram positif menggunakan media berbahan dasar air kelapa tua. Bahan uji yang digunakan adalah air kelapa tua yang terbuang percuma dan menjadi limbah. Bahan uji tersebut dikomposisikan menyerupai komposisi agar MacConkey dan LAD, dengan prosedur pembuatan modifikasi agar MacConkey (M1), yaitu agar bacto $15 \mathrm{~g}$, laktosa $10 \mathrm{~g}$, merah netral $0,075 \mathrm{~g}$, air kelapa ditambahkan sampai volume $1 \mathrm{~L}$, dan $\mathrm{KOH} 40 \%$ tetes per tetes sampai $\mathrm{pH} 7 \pm 2$. Campuran tersebut dididihkan sambil diaduk hingga homogen. Media disterilkan dengan autoklaf, kemudian dituang ke dalam cawan petri steril sebanyak $20 \mathrm{~mL} .^{9-11}$ Prosedur pembuatan modifikasi LAD (M2), yaitu agar bacto $15 \mathrm{~g}$, air kelapa ditambahkan sampai volume $1 \mathrm{~L}$, dan $\mathrm{KOH} 40 \%$ tetes per tetes sampai $\mathrm{pH} 7 \pm 2$. Campuran tersebut dididihkan sambil diaduk hingga homogen. Media disterilkan dengan autoklaf. Media didinginkan sampai suhu 45-50 ${ }^{\circ} \mathrm{C}$, kemudian ditambah darah $5 \%$, lalu dituang ke dalam cawan petri steril sebanyak 20 $\mathrm{mL} .{ }^{9-13}$

Media standar yang digunakan adalah agar MacConkey (S1) untuk Enterobacteriaceae dan LAD (S2) untuk kokus gram positif. Media kontrol yang digunakan adalah media agar 15 $\mathrm{g} / \mathrm{L}$ dan media agar air kelapa tua. Prosedur pembuatan media agar $15 \mathrm{~g} / \mathrm{L}$ (K1), yaitu agar bacto $15 \mathrm{~g}$ dan akuades yang ditambahkan sampai volume satu L. Agar bacto hanya mengandung bahan-bahan inorganik yang sangat sedikit, sehingga diharapkan tidak mengganggu proses peragian atau degradasi enzimatik bakteri terhadap substrat tertentu. Campuran tersebut dididihkan sambil diaduk hingga homogen. Media disterilkan dengan autoklaf, kemudian dituang ke dalam cawan petri steril sebanyak 20 $\mathrm{mL}$. Prosedur pembuatan media agar air kelapa (K2), yaitu agar bacto $15 \mathrm{~g}$, air kelapa yang ditambahkan sampai volume $1 \mathrm{~L}$, dan $\mathrm{KOH} 40 \%$ tetes per tetes sampai $\mathrm{pH} 7 \pm 2$. Campuran tersebut dididihkan sambil diaduk hingga homogen. Media disterilkan dengan autoklaf, kemudian dituang ke dalam cawan petri steril sebanyak $20 \mathrm{~mL}$. Bakteri uji yang digunakan adalah Escherichia coli, Klebsiella pneumoniae, Salmonella typhi, Salmonella paratyphi A, Shigella dysenteriae, Proteus mirabilis, Staphylococcus aureus, dan streptokokus $\beta$ hemolitik. Bakteri uji diambil dari bahan pemeriksaan, sudah diisolasi, dan berumur 24 jam. Bakteri uji ditanam pada media yang telah dibuat, kemudian diinkubasi selama 1×24 jam pada suhu $35 \pm 2^{\circ} \mathrm{C}$. Percobaan dilakukan dengan pengulangan sebanyak tiga kali. Pengamatan yang dilakukan adalah pengamatan gambaran makro dan mikroskopis. Pengamatan mikroskopis dilakukan dengan pewarnaan gram 
untuk semua bakteri uji dan Gins-Burri khusus untuk K. pneumoniae.

Semua data dikumpulkan dan diolah secara statistik dengan menggunakan metode Wilcoxon matched pairs test dan sign test.

\section{Hasil}

Pada perbandingan agar MacConkey (S1) tampak bahwa bakteri uji peragi laktosa $(E$. coli dan K. pneumoniae) membentuk koloni berwarna merah. Gambaran mukoid juga tampak pada koloni K. pneumoniae. S. typhi, S. paratyphi, dan $P$. mirabilis membentuk koloni tidak berwarna, sedangkan $S$. dysenteriae membentuk koloni berwarna oranye muda. Gambaran swarming P. mirabilis tampak jelas. Pemeriksaan secara mikroskopis menunjukkan gram negatif pada semua bakteri uji Enterobacteriaceae dan kapsul pada $K$. pneumoniae.

Pada modifikasi agar MacConkey (M1) tampak E. coli dan $K$. pneumoniae membentuk koloni yang sama dengan gambaran koloni pada $\mathrm{S} 1$, yaitu berwarna merah dengan gambaran mukoid $K$. pneumoniae yang tampak jelas. Salmonella typhi dan S. paratyphi membentuk koloni tidak berwarna. Shigella dysenteriae membentuk koloni berwarna merah. Proteus mirabilis membentuk koloni berwarna merah muda dengan swarming yang tampak jelas. Pemeriksaan secara mikroskopis menunjukkan hasil yang sama dengan S1, yaitu gram negatif pada semua bakteri uji Enterobacteriaceae dan kapsul pada K. pneumoniae.

Pada Tabel 1 tidak terdapat perbedaan bermakna $(p>0,05)$ gambaran makroskopis dan mikroskopis antara S1 dan M1. Beberapa foto hasil M1 dapat dilihat pada Gambar 1.

Pada perbandingan LAD (S2) tampak bahwa $S$. aureus dan streptokokus $\beta$ hemolitik membentuk koloni berwarna putih dan berukuran $1 \mathrm{~mm}$. Bakteri uji $S$. aureus tidak tampak membentuk zona hemolitik. Streptokokus $\beta$ hemolitik tampak membentuk zona hemolitik jernih transparan dengan ukuran zona $1 \mathrm{~mm}$. Setelah proses inkubasi, warna media S2 tidak berubah. Pemeriksaan mikroskopis menunjukkan kokus gram positif.

Pada modifikasi LAD (M2) tampak bahwa $S$. aureus membentuk koloni berwarna putih kecoklatan, ukuran $1 \mathrm{~mm}$, dan tampak zona hemolitik jernih kecoklatan dengan ukuran zona kurang dari $1 \mathrm{~mm}$. Streptokokus $\beta$ hemolitik membentuk koloni berwarna coklat, ukuran kurang dari $1 \mathrm{~mm}$, dan tampak zona hemolitik jernih kecoklatan dengan ukuran zona kurang dari $1 \mathrm{~mm}$. Setelah proses inkubasi, warna media M2 berubah menjadi kecoklatan. Pemeriksaan secara mikroskopis menunjukkan kokus gram positif.

Pada Tabel 2 dapat dilihat perbedaan yang tidak bermakna $(p>0,05)$ gambaran makroskopis dan mikroskopis antara S2 dan M2, sedangkan beberapa foto kokus gram positif pada M2 dapat dilihat pada Gambar 2 .

Pada media agar $15 \mathrm{~g} / \mathrm{L}(\mathrm{K} 1)$, tidak mengandung air kelapa tua, tidak didapatkan pertumbuhan bakteri uji, sedangkan pada media agar air kelapa tua (K2) terdapat pertumbuhan hampir semua bakteri uji, kecuali streptokokus $\beta$ hemolitik. Bakteri-bakteri uji membentuk koloni berwarna putih, kecuali $S$. typhi dan $S$. paratyphi yang membentuk koloni tidak berwarna. Gambaran mukoid K. pneumoniae dan swarming P. mirabilis tampak jelas pada K2.

Tabel 1 Perhitungan Uji Hipotesis berdasarkan Skoring Gambaran Makroskopis dan Mikroskopis pada S1 dan M1

\begin{tabular}{ccccc}
\hline Variabel dependen & Valid N & T & Z & p \\
\hline Makroskopis S1 dan makroskopis M1 & 6 & 0,00 & 1,825742 & 0,067 (tidak bermakna) \\
Mikroskopis S1 dan mikroskopis M1 & 6 & 0,00 & 1,825742 & 0,067 (tidak bermakna) \\
\hline
\end{tabular}

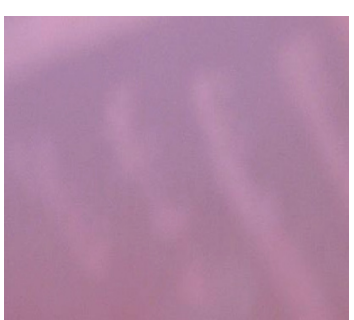

A

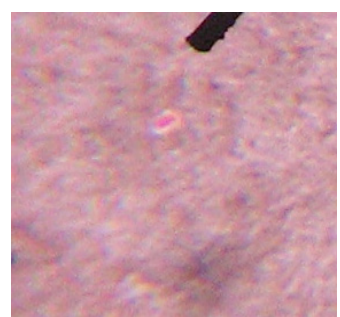

B

Gambar 1 Gambaran Makroskopis dan Mikroskopis Klebsiella pneumoniae pada Media M1

(A) Tampak koloni berwarna merah dengan gambaran mukoid

(B) Tampak gambaran kapsul pada pewarnaan Ginns-Burri 
Tabel 2 Perhitungan Uji Hipotesis berdasarkan Skoring Gambaran Makroskopis dan Mikroskopis pada S2 dan M2

\begin{tabular}{ccccc}
\hline Variabel dependen & N & Percent $\mathbf{v}<\mathbf{V}$ & $\mathbf{Z}$ & $\mathbf{p}$ \\
\hline Makroskopis S2 dan makroskopis M2 & 2 & 50,0 & $-0,7071$ & 0,479 (tidak bermakna) \\
Mikroskopis S2 dan mikroskopis M2 & 2 & 0,00 & 0,7071 & 0,479 (tidak bermakna) \\
\hline
\end{tabular}

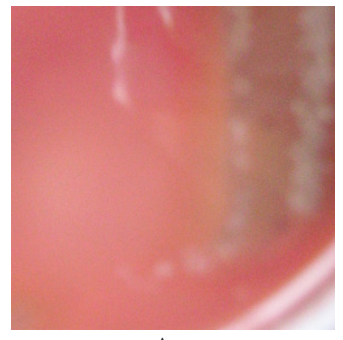

A

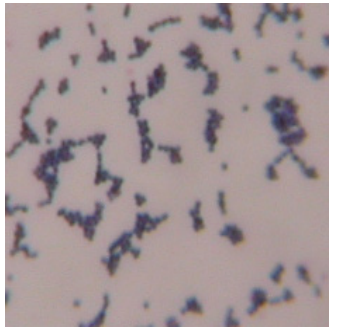

B

Gambar 2 Gambaran Makroskopis dan Mikroskopis Staphylococcus aureus pada Media M2

(A) Tampak koloni berwarna putih kecoklatan, ukuran $1 \mathrm{~mm}$, zona hemolitik jernih kecoklatan

(B) Tampak gambaran mikroskopis kokus gram positif

Gambaran mikroskopis menunjukkan hasil yang sesuai dengan karakteristik bakteri, yaitu gram negatif pada Enterobacteriaceae, gram positif pada $S$. aureus, dan gambaran kapsul $K$. pneumoniae yang tampak jelas.

Pada Tabel 3 dapat dilihat perbedaan hasil yang bermakna $(p=0,017)$ antara $K 1$ dan $K 2$. Beberapa foto bakteri uji pada K2 dapat dilihat pada Gambar 3.

\section{Pembahasan}

Hasil pada modifikasi agar MacConkey (M1) menunjukkan beberapa bakteri yang tidak meragi laktosa membentuk koloni berwarna merah. Hal ini disebabkan karena kandungan zat-zat bukan laktosa pada air kelapa tua mengalami proses fermentasi menghasilkan asam yang mengabsorbsi zat warna merah netral dan membentuk koloni berwarna merah. Walaupun pada modifikasi ini sudah dilakukan penambahan laktosa $10 \mathrm{~g} / \mathrm{L}$ yang diharapkan dapat mendominasi kandungan gula, namun fermentasi gula lain yang terdapat pada air kelapa tetap terjadi. Klebsiella pneumoniae pada M1 mampu membentuk koloni yang mukoid sebaik agar MacConkey (S1). Proteus mirabilis pada M1 mampu membentuk swarming yang tampak jelas.

Berdasarkan Wilcoxon matched pairs test yang membandingkan antara S1 dan M1 didapatkan nilai p yang tidak bermakna $(p=0,067)$ untuk gambaran

Tabel 3 Perhitungan Uji Hipotesis Berdasarkan Skoring Gambaran Makroskopis dan Mikroskopis pada $\mathrm{K} 1$ dan $\mathrm{K} 2$

\begin{tabular}{lcccc}
\hline Variabel dependen & Valid N & T & Z & p \\
\hline Makroskopis K1 dan makroskopis K2 & 8 & 0,00 & 2,366432 & 0,017 (bermakna) \\
Mikroskopis K1 dan mikroskopis K2 & 8 & 0,00 & 2,366432 & 0,017 (bermakna) \\
\hline
\end{tabular}

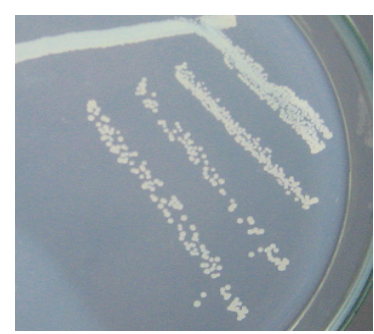

A

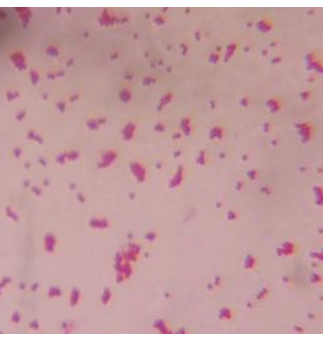

B

Gambar 3 Gambaran Makroskopis dan Mikroskopis Shigella dysenteriae pada Media K2

(A) Tampak koloni berwarna putih

(B) Tampak gambaran bakteri gram negatif 
makroskopis dan mikroskopis, maka dapat disimpulkan bahwa air kelapa tua dapat digunakan sebagai bahan dasar media yang dikomposisikan menyerupai agar MacConkey dengan penambahan laktosa dan merah netral (Tabel 1).

Hasil modifikasi LAD (M2) menunjukkan $S$. aureus dan streptokokus $\beta$ hemolitik dapat tumbuh dengan subur dan menghasilkan zona hemolitik yang berwarna kecoklatan. Berdasarkan sign test yang membandingkan antara LAD (S2) dan M2 didapatkan nilai $\mathrm{p}$ yang tidak bermakna $(p=0,479)$ untuk gambaran makroskopis maupun mikroskopis, maka dapat disimpulkan bahwa air kelapa tua dapat digunakan sebagai bahan dasar media yang dikomposisikan menyerupai LAD dengan penambahan darah (Tabel 2).

Pada media agar $15 \mathrm{~g} / \mathrm{L}$ (K1) tidak didapatkan pertumbuhan bakteri uji, karena pada media ini tidak terdapat kandungan bahan organik yang merupakan bahan utama yang dibutuhkan untuk pertumbuhan bakteri. Hampir semua bakteri uji dapat tumbuh pada media agar air kelapa tua (K2), karena air kelapa mengandung nutrisi yang diperlukan untuk pertumbuhan bakteri, terutama kandungan karbohidrat, protein, dan lemak. Streptokokus $\beta$ hemolitik tidak tumbuh pada K2, karena bakteri ini memerlukan nutrisi lebih untuk tumbuh seperti darah atau serum..$^{8-15}$ Berdasarkan Wilcoxon matched pairs test yang membandingkan antara K1 dan K2 didapatkan nilai p yang bermakna $(\mathrm{p}=0,017)$, baik untuk gambaran makroskopis maupun mikroskopis, maka dapat disimpulkan bahwa air kelapa tua dapat digunakan sebagai bahan dasar media. (Tabel 3).

Air kelapa tua sangat baik untuk pertumbuhan bakteri karena kandungan zat gizinya. Hal ini dapat dilihat pada hasil agar air kelapa tua (K2). Oleh karena itu, air kelapa dapat digunakan untuk bahan dasar media. Penggunaan air kelapa tua yang dicampur darah memberikan gambaran koloni dan zona hemolitik, sehingga dapat digunakan untuk bahan dasar alternatif LAD. Penggunaan air kelapa tua sebagai bahan dasar alternatif agar MacConkey memberikan hasil yang baik.

Simpulan, air kelapa tua dapat dipakai sebagai bahan dasar media isolasi Enterobacteriaceae dan kokus gram positif. Pemanfaatan media air kelapa tua sebagai bahan dasar media isolasi perlu dicobakan untuk isolasi bakteri dari bahan pemeriksaan langsung dan diaplikasikan untuk diagnostik klinik mikrobiologi, karena sifatnya yang ekonomis dan mudah didapat.

\section{Daftar Pustaka}

1. Chandra S. Medical device regulatory requirements for Indonesia 2001 (diunduh 3
Mei 2008). Tersedia dari: URL: http:// www. ita.doc.gov/td/ health/indonesia regs.html

2. Gross A. Indonesia year-end medical device market update 2007 (diunduh 9 Juni 2008). Tersedia dari: URL: http://www. pacificbridgemedical.com/ publications.html

3. Astawan M. Nata de coco yang kaya serat 2004 (diunduh 3 Mei 2008). Tersedia dari: URL: http://www.kompas.com/kesehatan/ news/0402/25/213558.html

4. Esti, Sawedi. Teknologi tepat guna 2001 (diunduh 3 Mei 2008). Tersedia dari: URL: http://www.iptek.net.id/ind/warintek/ pengolahan_pengan_id x.php?doc $=6 \mathrm{a} 9$

5. Sevilla VB. The utilization of the coconut water egg malachite green medium (CEM) for the isolation of Mycobacterium tuberculosis and Corynebacterium diphtheriae. Phil J Microbiol Infect Dis. 2001;10(2):93-7.

6. Rockhill RC, Sevilla VB, Sumarmo, Muslihun B, Siregar SP, Hadiputranto H. A new coconut water-tellurite-egg-medium (CTEM) to culture Corynebacterium diphtheriae. Phil J Microbiol Infect Dis. 2001;10(1):21-4.

7. Manuselis G, Mahon CR. Enterobacteriaceae. Dalam: Mahon CR, Manuselis G, penyunting. Textbook of diagnostic microbiology. Edisi ke-2. Philadelphia: W.B. Saunders Company; 2000. hlm. 464-99.

8. Forbes BA, Sahm DF, Weissfeld AS. Bailey \& Scott's. Diagnostic microbiology. Edisi ke-1. London: Mosby, Inc.; 2002.

9. Bridson EY. The oxoid manual. Edisi ke-9. Hampshire: Oxoid Limited; 2006.

10. Hargrave PK, Adams S. Selected bacteriologic culture media. Dalam: Mahon CR, Manuselis $\mathrm{G}$, penyunting. Textbook of diagnostic microbiology. Edisi ke-2. Philadelphia: W.B. Saunders Company; 2000. hlm. 1119-29.

11. Cappuccino JG, Sherman N. Microbiology a laboratory manual. Edisi ke-6. New York: Benjamin Cummings; 2002.

12. Mahon CR, Larsen HS. Staphylococci. Dalam: Mahon CR, Manuselis G, penyunting. Textbook of diagnostic microbiology. Edisi ke-2. Philadelphia: W.B. Saunders Company; 2000. hlm. 330-7.

13. Larsen HS. Streptococcaceae. Dalam: Mahon CR, Manuselis G, penyunting. Textbook of diagnostic microbiology. Edisi ke-2. Philadelphia: W.B. Saunders Company; 2000. hlm. 345-68.

14. Brooks GF, Butel JS, Morse SA. Jawetz, Melvick \& Adelberg's medical microbiology. Singapore: McGraw-Hill; 2004.

15. Prescott LM, Harley JP, Klein DA. Microbiology. Edisi ke-5. New York: McGraw-Hill; 2002. 